Article

\title{
Preparation and Properties of Co-Doped Magnesium Lanthanum Hexaluminat Blue Ceramics
}

\author{
Rui Guo ${ }^{1, *}$, Qingchun Wang ${ }^{1, *}$, Jinxiao Bao ${ }^{2}$ and Xiwen Song ${ }^{2}$ \\ 1 Institute of Materials and Metallurgy, Inner Mongolia University of Science and Technology, \\ Baotou 014010, China \\ 2 Key Laboratory of Advanced Ceramic Materials and Devices, Inner Mongolia Autonomous Region, \\ Baotou 014010, China; JXbao@163.com (J.B.); xiwensong@126.com (X.S.) \\ * Correspondence: rgrui199@126.com (G.R.); qingchun0221@126.com (Q.W.)
}

Received: 25 February 2020; Accepted: 6 May 2020; Published: 14 May 2020

check for updates

\begin{abstract}
The types of blue ceramics are monotonous, mainly alumina and zirconia ceramics, and their colors are not pure, with some green tones ( $-\mathrm{a}^{*}$ value is not close to 0$)$. In this paper, aluminate blue ceramics ( $\mathrm{LaMgAl} \mathrm{Al}_{11-\mathrm{x}} \mathrm{Co}_{\mathrm{x}} \mathrm{O}_{19}$ ) doped with $\mathrm{Co}$ were prepared by the high temperature solid-phase reaction method, which enriched the blue ceramics system. The effect of Co content on the color of ceramics was studied, and the optimal doping amount of Co was found. $X=1.0$ is the bluest color of the material $\left(-b^{*}=35.36\right)$, and there is almost no noise effect $\left(-a^{*}=-2.71\right)$. By studying the effect of temperature on the system, it is found that the color effect is best when the temperature reaches $1450{ }^{\circ} \mathrm{C}$. When the temperature exceeds $1450{ }^{\circ} \mathrm{C}$, it can only promote the synthesis of $\mathrm{LaMgAl}_{11} \mathrm{O}_{19}$ phase, and has no effect on the color of ceramics samples. Based on the material's pure and bright colors, and good color stability at room temperature, it has great potential in the decoration industry, such as the preparation of jewelry or building decoration materials.
\end{abstract}

Keywords: aluminate; solid phase reaction; doping; optical properties

\section{Introduction}

In recent years, colored ceramics have been widely used in the decoration industry, such as mobile phone back plates, bracelets, and cases [1]. The blue hue is bright and popular with the people, and there are many researches on blue ceramics. Toriumi et al. [2] studied the mixing enthalpy of $\mathrm{CoAl}_{2} \mathrm{O}_{4}$ solid solution blue material. Walsh et al. [3] studied the optical effects and optical catalytic properties of $\mathrm{CoAl}_{2} \mathrm{O}_{4}$ spinel. Zhi et al. [4] used alumina and cobalt oxide to synthesize spinel-type $\mathrm{CoAl}_{2} \mathrm{O}_{4}$ blue ceramics using a high-temperature solid-phase method, and found that calcining $\mathrm{m}(\mathrm{CoO})$ : $\mathrm{m}\left(\mathrm{Al}_{2} \mathrm{O}_{3}\right)=0.540$ at a sintering temperature of $1200^{\circ} \mathrm{C}$ can provide a better cobalt blue powder material. Lv HD, Bao JX et al. [5] Prepared blue-violet ceramics with $\mathrm{Co}$ as the coloring ion and $\mathrm{ZrO}_{2}$ as the toughening matrix. We find that the blue ceramics studied in recent decades are mainly alumina ceramics and $\mathrm{ZrO}_{2}$ ceramics. However, the color is not bright enough, as the chromaticity value of this system almost meets $-b^{*}<35$ (the larger the $-b^{*}$ value, the bluer the color), $-a^{*}>-10$ (the larger the -a value, the stronger the green tone) [1-6]. This means that the development of blue ceramics in other systems has great research value. $\mathrm{Mg}$-based lanthanum hexaaluminate $\left(\mathrm{LaMgAl} \mathrm{Al}_{11} \mathrm{O}_{19}\right)$ is a Hibonite structure with good thermal stability, optical properties, and catalytic properties [7]. There are many studies on the preparation methods of Mg-based lanthanum hexaaluminate materials. Zhu et al. [8] prepared $\mathrm{LaMgAl}_{11} \mathrm{O}_{19}$ powder with regular morphology and more uniform particle size by sol-gel method and solid-phase sintering method. He et al. [9] used solid-phase reaction method to synthesize magnesium-based lanthanum hexaaluminate $\left(\mathrm{LaMgAl}_{11} \mathrm{O}_{19}\right)$ for thermal barrier coatings with uniform particle size and good fluidity. The current research reports on $\mathrm{LaMgAl}_{11} \mathrm{O}_{19}$ are mainly focused on 
thermal barrier coatings and phosphor matrix materials [10,11], but few studies have been done with ceramic pigments or colored ceramics. Melo et al. [12] synthesized $\mathrm{La}_{1-\mathrm{x}} \mathrm{Ca}_{\mathrm{x}} \mathrm{CoO}_{3}(\mathrm{x}=0-0.4)$ pigment by polymer precursor method, and Jun Li et al. [13] studied the coloring potential of pyrite structure by replacing $\mathrm{Al}^{3+}$ in tetrahedron with $\mathrm{Ni}^{2+}$, but the chromaticity value $-\mathrm{b}^{*}$ is only around 18.5.

As we all know, transition elements have better coloring ability and are mostly used in the preparation of ceramic pigments [1-14]. In the present work, we have studied the $\mathrm{LaMgAl}_{11-\mathrm{x}} \mathrm{Co}_{\mathrm{x}} \mathrm{O}_{19}$ blue ceramics $(x=0.5,1.0,1.5,2.0,2.5)$ and explored the optimal doping amount of the system. In addition, the influence of sintering temperature on the synthesis of phase and the optical properties of the sample was studied, and the color stability of the sample at room temperature was tested. The results show that this kind of material is suitable for the preparation of barely leaking decorative materials, such as watches, bracelets, necklaces, and other architectural decorations.

\section{Experimental}

\subsection{Sample Preparation}

The initial raw materials are $\mathrm{La}_{2} \mathrm{O}_{3}$ (Hangzhou Wanjing Co., Ltd., Hangzhou, China, purity $\geq 99.99 \%$ ), $\mathrm{Al}(\mathrm{OH})_{3}, \mathrm{MgO}$ (Weifang Guanxu Chemical Co., Ltd., Shangdong, China, purity $\geq 99.99 \%$ ) and $\mathrm{Co}_{2} \mathrm{O}_{3}$ (Henan Zhengkai Chemical Co., Ltd, Henan, China). In order to remove the moisture contained in the raw materials, the purchased raw materials were calcined at $400{ }^{\circ} \mathrm{C}$ for $6 \mathrm{~h}$. Pre-calcined raw materials $\left(\mathrm{La}_{2} \mathrm{O}_{3}, \mathrm{Al}(\mathrm{OH})_{3}, \mathrm{MgO}\right.$ and $\left.\mathrm{Co}_{2} \mathrm{O}_{3}\right)$ are accurately weighed according to the stoichiometric ratio. The raw materials weighed according to the stoichiometric ratio are ball-milled in an ethanol environment for $24 \mathrm{~h}$, and then the mixed slurry that has been ball-milled for $24 \mathrm{~h}$ is transferred to a drying box at $75{ }^{\circ} \mathrm{C}$ for $12 \mathrm{~h}$ to remove the absolute ethanol in the slurry. The powder obtained after drying was ground with an agate mortar and pressed into a rough embryo with a Ø25 mold under a pressure of $20 \mathrm{MPa}$. The prepared crude embryo sample was sintered in air at $1450{ }^{\circ} \mathrm{C}$ for $3 \mathrm{~h}$ without pressure.

\subsection{Microstructural Characterization}

The phase structure of the cobalt-doped lanthanum hexaaluminate ceramic was determined, and the crystal lattice range of $20-80^{\circ}$ was detected by X-ray diffraction (XRD, BRUKER D8 ADVANCE, Germany) at a scanning speed of $2^{\circ} / \mathrm{min}$. We use the Jade software to analyze the measured XRD data, compare the diffraction peaks with a PDF card, and then use different symbols to mark the diffraction peaks that can match the PDF card. The microstructure indicated by the sample was characterized by a field emission scanning electron microscope (FE-SEM, Zeiss, Sigma 500), and the sample was sonicated in absolute ethanol for $50 \mathrm{~min}$ to remove impurities on the surface of the sample. The bulk density of the Mg-based lanthanum hexaaluminate ceramic sample in absolute ethanol was determined by Archimedes' principle, and the relative density was calculated. The theoretical density here is $4.268 \mathrm{~g} / \mathrm{cm}^{3}$ [15].

\subsection{Optical Performance Characterization}

The color of the blue lanthanum hexaaluminate ceramics were measured by the ultraviolet-visible spectrophotometer (UV-3900, Shanghai, China) from $200 \mathrm{~nm}$ to $800 \mathrm{~nm}$, and the spectrophotometer (CM-3600A, Konica Minolta Japan Co., Shenzhen, China.) characterizes the color change of the sample with increasing cobalt content. In the face of incident light, white samples will have total reflection in the range of ultraviolet and visible light (200-800 nm), black samples will be completely absorbed, and colored samples will have diffuse reflection in a specific range of ultraviolet and visible light. For example, the peak of the UV diffuse reflection of the cobalt blue colorant sample appears at 430-500 nm [16]. Make a tangent line at the reflection peak positions of all samples using the intercept 
line method, and then use Formula (1) to calculate the band gap value of each sample, where $E_{\mathrm{g}}$ is the band gap value of the sample, and $\lambda$ is the intersection of the tangent and the abscissa.

$$
E_{\mathrm{g}}=\frac{1240}{\lambda}(\mathrm{ev})
$$

CIE1976Lab uniform color space can be calculated using the following function formula.

$$
\begin{gathered}
\mathrm{L}^{*}=116\left(\frac{Y}{Y_{0}}\right)^{\frac{1}{3}}-16 \\
\mathbf{a}^{*}=500\left[\left(\frac{X}{X_{0}}\right)^{\frac{1}{3}}-\left(\frac{Y}{Y_{0}}\right)^{\frac{1}{3}}\right. \\
\mathbf{b}^{*}=200\left[\left(\frac{Y}{Y_{0}}\right)^{\frac{1}{3}}-\left(\frac{Z}{Z_{0}}\right)^{\frac{1}{3}}\right]
\end{gathered}
$$

In this functional formula, $X Y Z$ is the tristimulus value of the object color, and $X_{0} Y_{0} Z_{0}$ is the tristimulus value of the light source color. The colorimetric value $\left(\mathrm{L}^{*}, \mathrm{a}^{*}, \mathrm{~b}^{*}\right)$ of the samples were measured with a spectrophotometer, where $L^{*}$ represents the sample saturation, the larger the value of $\mathrm{L}^{*}$, the higher the saturation, the brighter the color observed by the naked eye, $\mathrm{a}^{*}$ Indicates that the samples appear red or green ( $\mathrm{a}^{*}>0$ is red, $\mathrm{a}^{*}<0$ is green), $\mathrm{b}^{*}$ indicates that the sample is yellow or blue ( $\mathrm{b}^{*}>0$ is yellow, $\mathrm{b}^{*}<0$ is blue).

\section{Result and Discussion}

\subsection{Phase Analysis}

Figure 1 shows the $\mathrm{XRD}$ patterns of $\mathrm{LaMgAl}_{11-\mathrm{x}} \mathrm{Co}_{\mathrm{x}} \mathrm{O}_{19}(\mathrm{x}=0.5,1.0,1.5,2.0,2.5)$ samples sintered in the air environment at $1450{ }^{\circ} \mathrm{C}$ for $3 \mathrm{~h}$. Obviously, for the five groups of samples, $\mathrm{LaMgAl} \mathrm{Al}_{11} \mathrm{O}_{19}$ is the main phase. Weak $\mathrm{CoAl}_{2} \mathrm{O}_{4}$ characteristic peaks were found at $2 \theta$ values of $31.4^{\circ}, 48.1^{\circ}, 55.7^{\circ}$, and $65.3^{\circ}$, and some traces of $\mathrm{LaAl}_{11} \mathrm{O}_{18}$ characteristic peaks were also found. The reason for this phenomenon is that according to most raw materials, $\mathrm{LaMgAl}_{11} \mathrm{O}_{19}$ will be obtained by reaction. A small amount of $\mathrm{Al}(\mathrm{OH})_{3}$ will change to $\mathrm{Al}_{2} \mathrm{O}_{3}$ as the temperature rises, and react with $\mathrm{La}_{2} \mathrm{O}_{3}$ to obtain $\mathrm{LaAl}_{11} \mathrm{O}_{18}$. The excess $\mathrm{Al}_{2} \mathrm{O}_{3}$ and $\mathrm{Co}_{2} \mathrm{O}_{3}$ will react to obtain $\mathrm{CoAl}_{2} \mathrm{O}_{4}$. The specific reaction process is shown in the following reaction formulas:

$$
\begin{gathered}
\mathrm{La}_{2} \mathrm{O}_{3}+2 \mathrm{MgO}+22 \mathrm{Al}(\mathrm{OH})_{3} \rightarrow 2 \mathrm{LaMgAl}_{11} \mathrm{O}_{19}+33 \mathrm{H}_{2} \mathrm{O} \uparrow \\
2 \mathrm{Al}(\mathrm{OH})_{3} \stackrel{800}{\rightarrow} \mathrm{Al}_{2} \mathrm{O}_{3}+\mathrm{H}_{2} \mathrm{O} \uparrow \\
\mathrm{La}_{2} \mathrm{O}_{3}+\mathrm{Al}_{2} \mathrm{O}_{3} \rightarrow 2 \mathrm{LaAlO}_{3} \\
\mathrm{La}_{2} \mathrm{O}_{3}+11 \mathrm{Al}_{2} \mathrm{O}_{3} \rightarrow 2 \mathrm{LaAl}_{11} \mathrm{O}_{18} \\
5 \mathrm{Al}_{2} \mathrm{O}_{3}+\mathrm{LaAl}_{11} \mathrm{O}_{18}+\mathrm{MgO} \rightarrow \mathrm{LaMgAl}_{11} \mathrm{O}_{19} \\
\mathrm{Co}^{3+} \rightarrow \mathrm{Al}^{3+} \\
\mathrm{Co}_{2} \mathrm{O}_{3}+2 \mathrm{Al}_{2} \mathrm{O}_{3} \rightarrow 2 \mathrm{CoAl}_{2} \mathrm{O}_{4}+\frac{1}{2} \mathrm{O}_{2} \uparrow
\end{gathered}
$$

With the increase of $\mathrm{Co}_{2} \mathrm{O}_{3}$ content, $\mathrm{Al}^{3+}$ in $\mathrm{LaMgAl}_{11} \mathrm{O}_{19}$ lattice is replaced by $\mathrm{Co}^{3+}$, and the remaining amount of $\mathrm{Co}_{2} \mathrm{O}_{3}$ increases, which leads to the enhancement of the diffraction peak of $\mathrm{CoAl}_{2} \mathrm{O}_{4}$. 


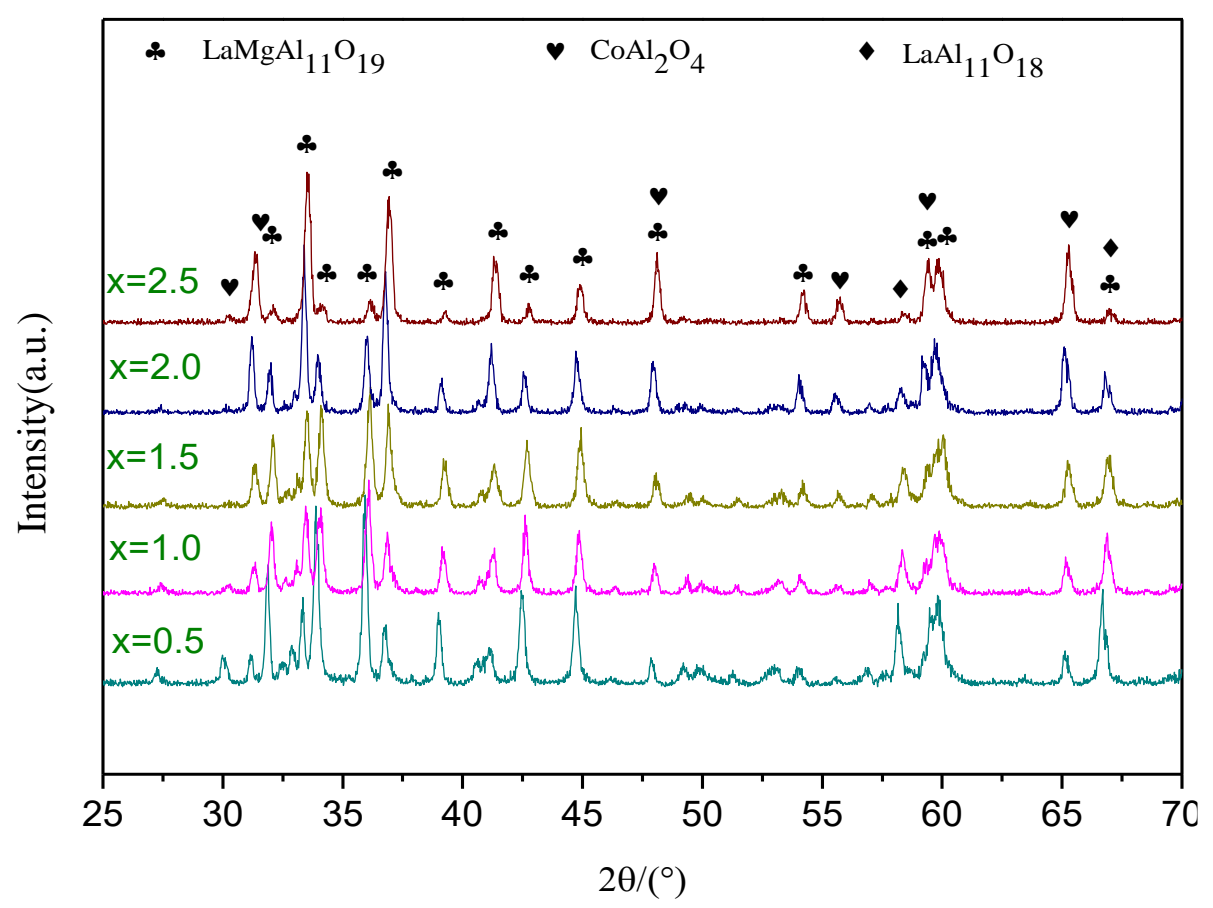

Figure 1. X-ray spectra of different Co contents of Mg-based lanthanum hexaaluminate samples prepared at $1450{ }^{\circ} \mathrm{C}$.

Figure 2 shows a FE-SEM image of a Co-doped magnesium-based lanthanum hexaaluminate ceramics sintered at $1450{ }^{\circ} \mathrm{C}$. The polyhedral $\mathrm{CoAl}_{2} \mathrm{O}_{4}$ phase and lamellar $\mathrm{LaMgAl}_{11} \mathrm{O}_{19}$ phase can be found in the figure. At the same time, it was found that with the increase of the Co content, the phase content of $\mathrm{CoAl}_{2} \mathrm{O}_{4}$ gradually increased, and the compactness of the samples gradually decreased $[17,18]$, which was consistent with the bulk density change values recorded in Table 1 . When $x=2.0$, obvious pores appear on the ceramic surface, which may be caused by the soft and porous structure of $\mathrm{CoAl}_{2} \mathrm{O}_{4}$ [19].

Table 1. With the increase of cobalt content, the density change value of Mg-based lanthanum hexaaluminate.

\begin{tabular}{ccc}
\hline $\mathrm{Co}_{2} \mathrm{O}_{3} /(\mathbf{w t} \%)$ & Volume Density/(g/cm $\left.{ }^{3}\right)$ & Relative Density/(\%) \\
\hline $\mathrm{x}=0.5$ & 3.79 & 88.88 \\
$\mathrm{x}=1.0$ & 3.71 & 86.92 \\
$\mathrm{x}=1.5$ & 3.65 & 85.55 \\
$\mathrm{x}=2.0$ & 3.53 & 82.71 \\
$\mathrm{x}=2.5$ & 3.47 & 81.30 \\
\hline
\end{tabular}



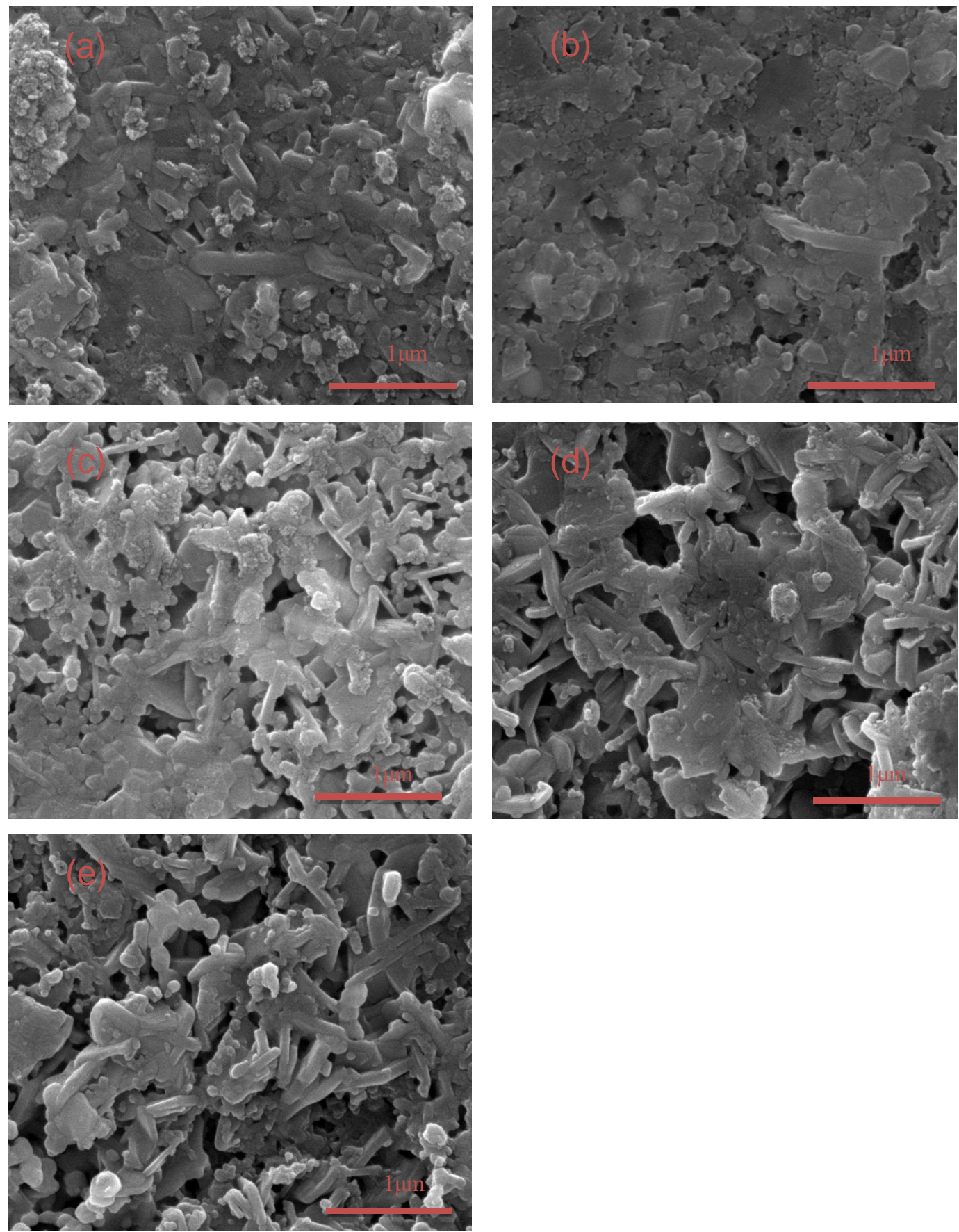

Figure 2. SEM images of Mg-based lanthanum hexaaluminate with different Co doping amounts. (a) $\mathrm{x}=0.5,(\mathbf{b}) \mathrm{x}=1.0,(\mathbf{c}) \mathrm{x}=1.5,(\mathbf{d}) \mathrm{x}=2.0,(\mathbf{e}) \mathrm{x}=2.5$.

\subsection{The Diffuse Reflectance and the Chromatic Properties}

The blue Mg-based lanthanum aluminate ceramics prepared by experiments were pure blue and uniform in color. Figure 3 shows the UV-vis diffuse reflection spectrum of Co-doped $\mathrm{LaMgAl}_{11} \mathrm{O}_{19}$ ceramics. With the increase of Co content, the reflectance gradually decreases, the reflectance decreases from about $50 \%$ to $25 \%$, and the sample color brightness decreases. The figure shows that the sample has strong diffuse reflection at about $431 \mathrm{~nm}$, and the absorption peak appears at $494 \mathrm{~nm}$. The samples reflect blue light and absorbs light other than blue light. All samples found very small absorption peaks at the $475 \mathrm{~nm}$ position. This may be caused by the $\mathrm{CoAl}_{2} \mathrm{O}_{4}$ spinel phase absorbing visible light around $430 \mathrm{~nm}$ and overlapping with the diffraction peaks of $\mathrm{LaMgAl}_{11-\mathrm{x}} \mathrm{Co}_{\mathrm{x}} \mathrm{O}_{19}$ [20]. All samples 
have a strong reflection in the visible range after the $725 \mathrm{~nm}$ position, which increases the brightness of the sample. The intercept method was used to calculate the forbidden band width of each sample, and each sample was calculated and averaged multiple times. After collating the data, the relationship between Co content and forbidden band width $\left(E_{\mathrm{g}}\right)$ is obtained, as shown in Figure 4 . In the figure, we find that the band width of the sample increases with the increase of the Co content, indicating that the color of the sample becomes darker when the band width increases within a certain range.

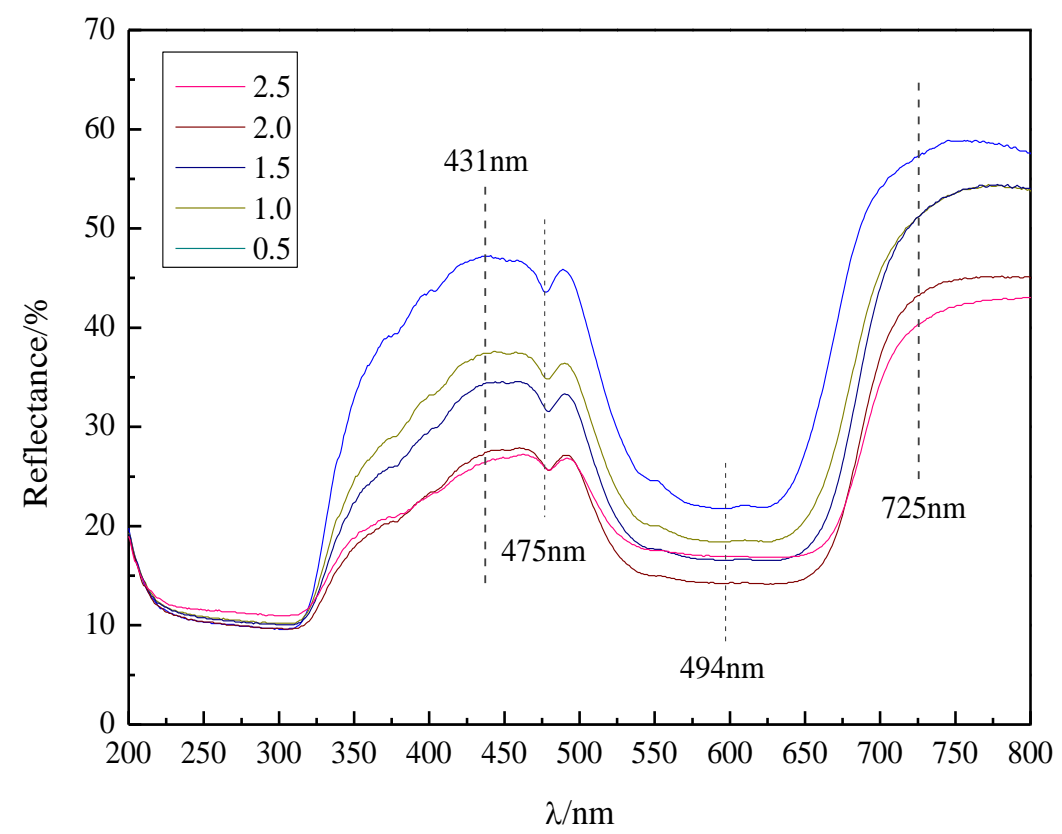

Figure 3. UV-Vis diffuse reflection of $\mathrm{Mg}$-based lanthanum hexaaluminate samples prepared at $1450{ }^{\circ} \mathrm{C}$ under different Co contents.

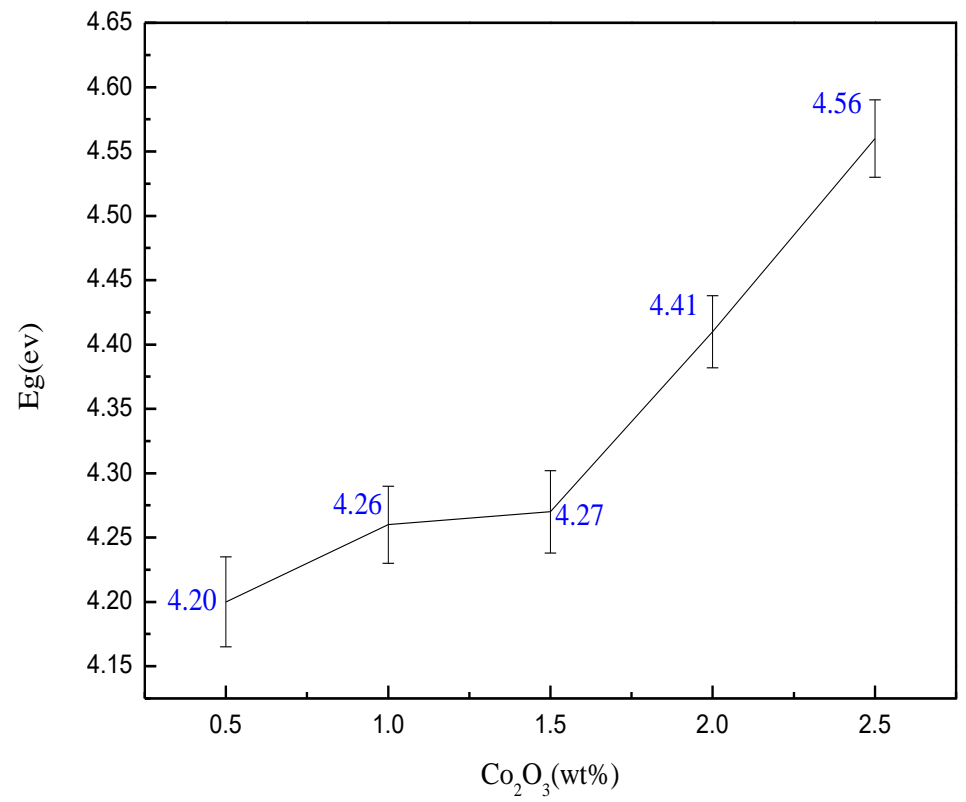

Figure 4. The relationship between the band gap and the Co content of Mg-based lanthanum hexaaluminate samples prepared at $1450{ }^{\circ} \mathrm{C}$.

The color coordinate values $\left(\mathrm{L}^{*}, \mathrm{a}^{*}\right.$ and $\left.\mathrm{b}^{*}\right)$ and chromaticity change curves of the synthesized lanthanum aluminate ceramics are shown in Table 2 and Figure 5 . It can be seen from Figure 5 that $L^{*}$ shows a downward trend with the increase of the content of $\mathrm{Co}$, and the color of the sample becomes 
darker. The $a^{*}$ values of all samples are distributed around 0 , and the $-b^{*}$ values representing blue are greater than 20, and they increase first and then decrease. When $x=1.0$, the maximum value of 35.36 is reached, and the sample has the strongest blue hue. Jun Li et al. [13] Prepared the $\mathrm{LaAl}_{11} \mathrm{NiO}_{19}$ material with a blue tone of $-b^{*}=23$. It can be seen that the magnesium-based lanthanum hexaaluminate material we prepared is relatively blue and bright. The physical picture of the sample is shown in Figure 6. In summary, when the doping amount is $x=1.0$, the sample band gap value $E_{g}=4.26$. At this time, the bluest ceramic is obtained.

Table 2. Chromaticity changes of Mg-based lanthanum hexaaluminate with different cobalt contents.

\begin{tabular}{cccc}
\hline $\mathbf{C o}_{\mathbf{2}} \mathbf{O}_{\mathbf{3}} \mathbf{( \mathbf { w t } \% )}$ & $\mathbf{L}^{*}$ & $\mathbf{a}^{*}$ & $\mathbf{b}^{*}$ \\
\hline $\mathrm{x}=0.5$ & 54.33 & -3.87 & -34.02 \\
$\mathrm{x}=1.0$ & 47.81 & -3.17 & -35.36 \\
$\mathrm{x}=1.5$ & 44.14 & -2.71 & -34.11 \\
$\mathrm{x}=2.0$ & 40.98 & -2.07 & -26.89 \\
$\mathrm{x}=2.5$ & 38.93 & -2.43 & -23.53 \\
\hline
\end{tabular}

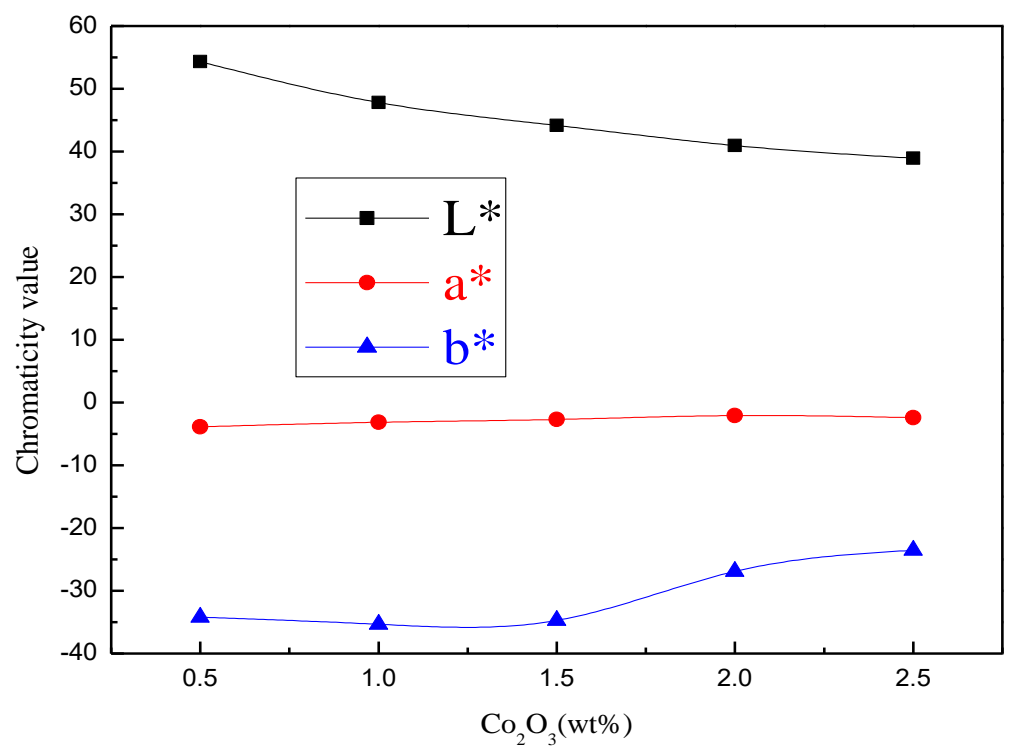

Figure 5. The chromaticity change curves of different $\mathrm{Mg}$-based lanthanum hexaaluminate samples with different Co contents prepared at $1450{ }^{\circ} \mathrm{C}$.
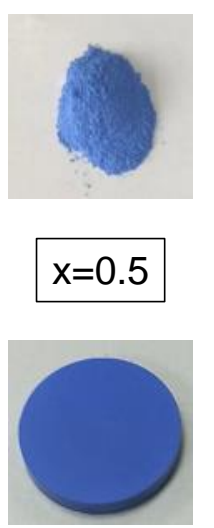
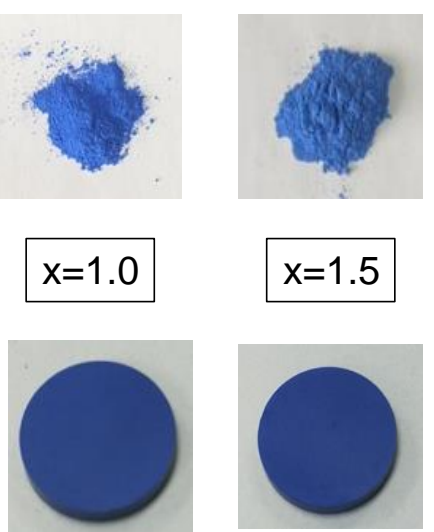

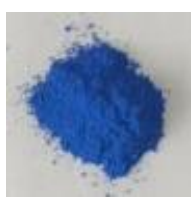

$$
x=2.0
$$

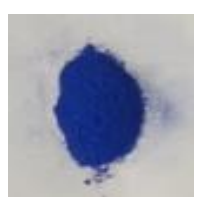

$$
x=2.5
$$
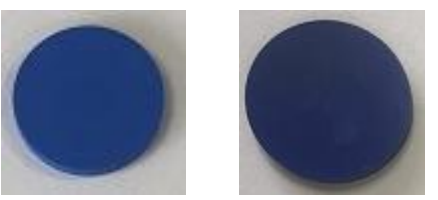

Figure 6. A photo of $\mathrm{LaMgAl}_{11-\mathrm{x}} \mathrm{Co}_{\mathrm{x}} \mathrm{O}_{19}$ powder material and magnesium-based lanthanum hexaaluminate blue ceramics. 


\subsection{Influence of Other Factors on the Optimal Doping Amount}

Figure 7 shows the effect of temperature on the optimal doping amount of $\mathrm{LaMgAl}_{11-\mathrm{x}} \mathrm{Co}_{\mathrm{x}} \mathrm{O}_{19}$. Unsintered samples with optimal doping amount $\mathrm{x}=1.0$ were selected and calcined at $1350{ }^{\circ} \mathrm{C}, 1450{ }^{\circ} \mathrm{C}$, and $1550^{\circ} \mathrm{C}$, respectively. Their X-ray diffraction (Figure 7a) and optical properties (Figure $7 \mathrm{~b}$ ) were examined. Figure $7 \mathrm{a}$ shows that $\mathrm{LaMgAl}_{11} \mathrm{O}_{19}$ is the main phase in these three samples calcined at different temperatures. The diffraction peak intensity of $\mathrm{CoAl}_{2} \mathrm{O}_{4}$ gradually decreases with increasing temperature, which may be caused by the volatile Co element at high temperature [21]. It is found from Figure $7 \mathrm{~b}$ that the temperature has a certain effect on the brightness of the sample. The sintered sample at $1450^{\circ} \mathrm{C}$ is significantly bluer than the sample prepared at $1350{ }^{\circ} \mathrm{C}$. The blue tone does not increase significantly at $1550^{\circ} \mathrm{C}$. Considering the energy consumption, we found that it is more reasonable to calcine the sample at $1450^{\circ} \mathrm{C}$. Figure 8 shows the change of sample color when the best-doped sample $(\mathrm{x}=1.0)$ calcined at $1450{ }^{\circ} \mathrm{C}$ was placed in air at normal temperature for different times. It was found that the sample that was just out of the oven was left in the air for 0.8 years, and the color of the sample did not change, which indicates that this sample has good color stability at room temperature.
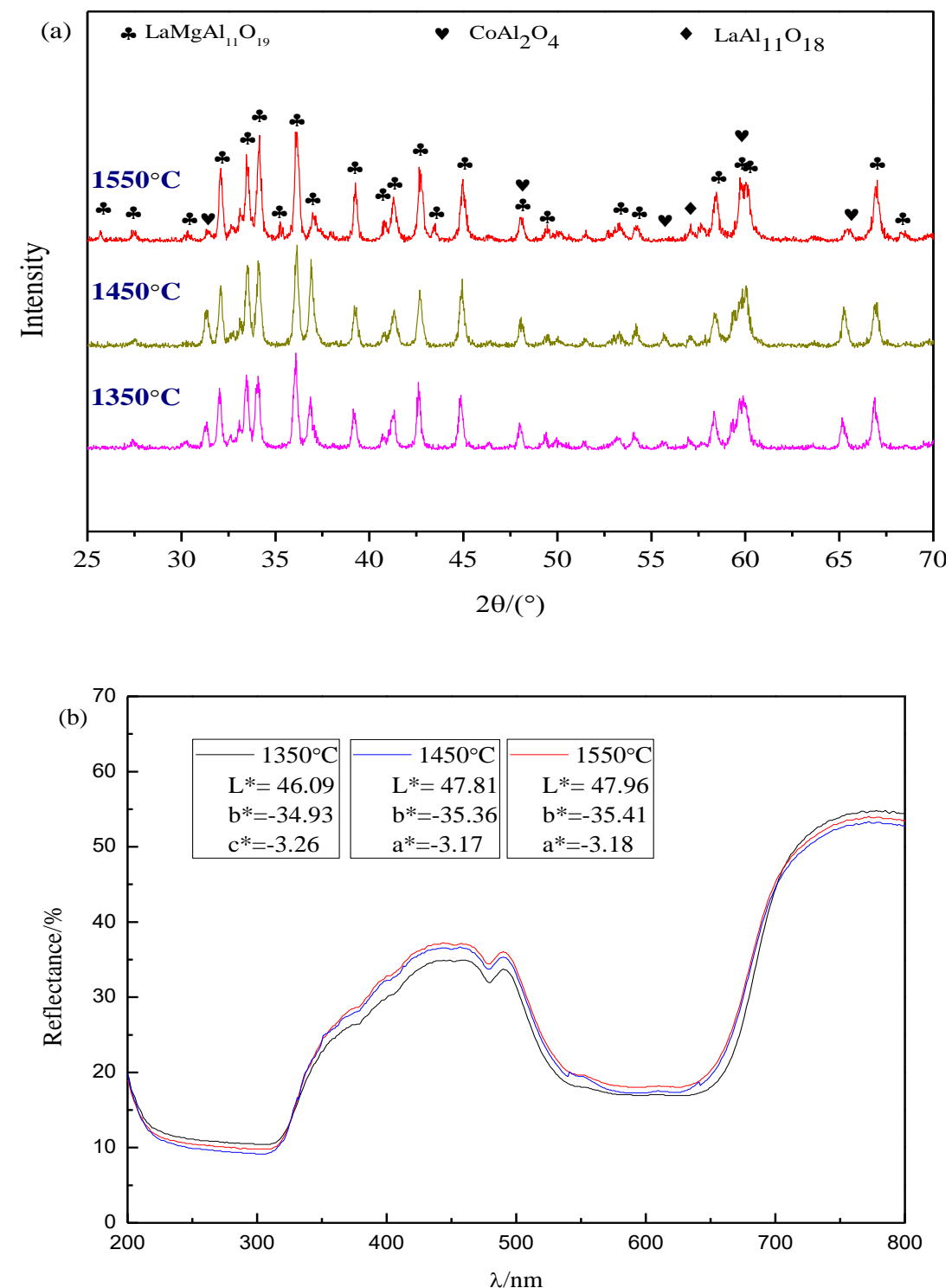

Figure 7. Effect of different temperatures on the performance of the best color sample $(x=1.0)$. (a) Effect of temperature on the phase of the sample. (b) Effect of temperature on the optical properties of the sample. 


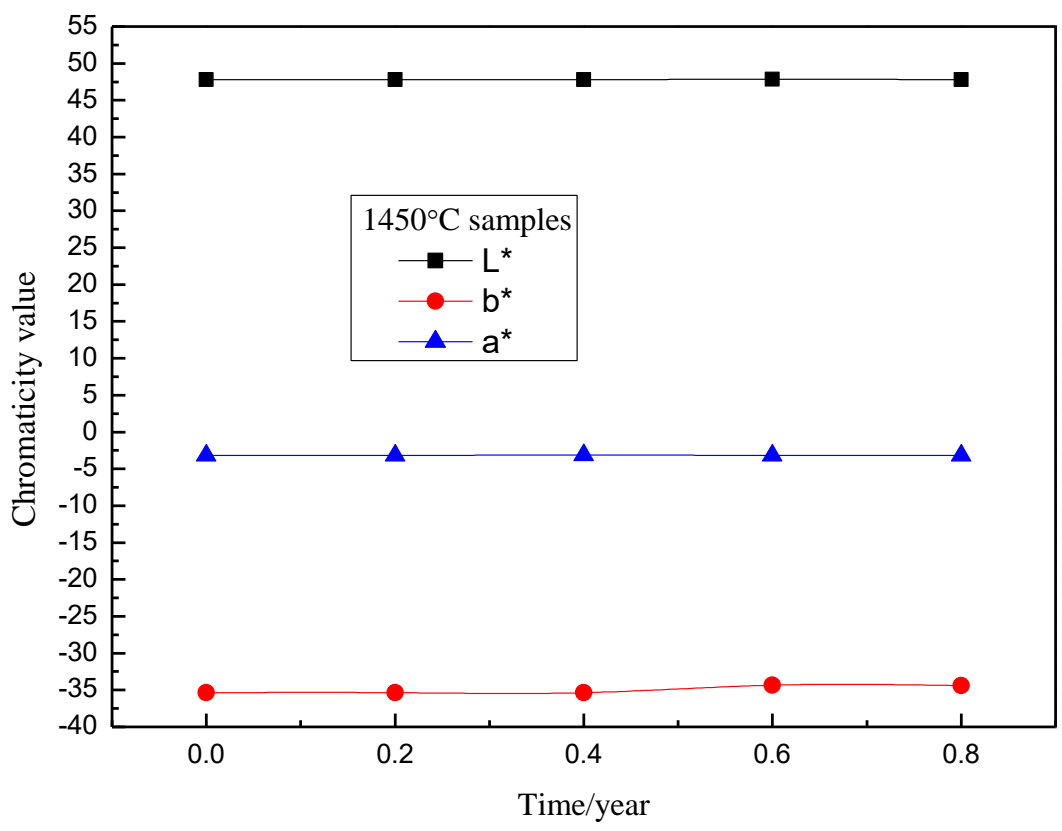

Figure 8. Chroma stability of samples with optimal doping amount at room temperature.

\section{Conclusions}

In this paper, cobalt-doped $\mathrm{Mg}$-based lanthanum hexaaluminate ceramics were prepared by a solid-phase high-temperature reaction method. The effects of doping amount and temperature on optical properties were studied, and the stability of the samples at room temperature was analyzed. The specific conclusions are as follows:

(1) The doping content of Co is the key factor for the color development of the sample, and $x=1.0$ is the optimal doping amount. At this time, the blue tone of the sample $-\mathrm{b}^{*}$ reached the maximum value $\left(-b^{*}=35.36\right)$.

(2) The forbidden band width also plays a certain role in the color development of the sample. When $E_{\mathrm{g}}=4.26 \mathrm{ev}$ in this system, the sample color is the bluest.

(3) Increasing the temperature can promote the synthesis of the phase, thereby increasing the color depth of the sample. In this system, the color of the sample reaches the deepest at $1450{ }^{\circ} \mathrm{C}$. Continuing to increase the temperature will only promote the synthesis of the phase with little effect on the color of the sample.

(4) This material can maintain color stability when exposed to air, and can be used to prepare various jewelry and decorative items.

Author Contributions: X.S. and J.B. provided the experimental platform and the purchase of medicine bottles for the experiment. Q.W. provided the experimental plan and certain experimental guidance for this experiment. R.G. completed the operation and analysis of the entire experiment and the writing of the paper. All authors have read and agreed to the published version of the manuscript.

Funding: This research was funded by Qingchun Wang.

Acknowledgments: This work was financially supported by the National Natural Science Foundation of China (51762036), Inner Mongolia Natural Science Foundation (2017BS0504, 2017MS0221 and Inner Mongolia Autonomous Region Higher Education School "Youth Technical Talent Support Program" Category A (NJYT-19-A20).

Conflicts of Interest: The authors declare no conflict of interest. 


\section{References}

1. Lv, H.D.; Bao, J.X.; Ruan, F.; Zhou, F. Preparation and properties of black Ti-doped zirconia ceramics. J. Mater. Res. Technol. 2020, 1, 19-23. [CrossRef]

2. Toriumi, K.; Ozima, M.; Akaogi, M. Electron-density distribution in crystals of $\mathrm{CoAl}_{2} \mathrm{O}_{4}$. Acta Crystallogr. Sect. B Struct. Sci. 1978, 34, 1093-1096. [CrossRef]

3. Walsh, A.; Yan, Y.; Al-Jassim, M.M. Electronic, Energetic, and Chemical Effects of Intrinsic Defects and Fe-Doping of $\mathrm{CoAl}_{2} \mathrm{O}_{4}$ : A DFT+U Study. J. Phys. Chem. C 2008, 112, 12044-12050. [CrossRef]

4. $\quad \mathrm{Fu}, \mathrm{W}$; Yuan, Z.; Chen, K.Y. High-temperature solid-phase synthesis of spinel-type $\mathrm{CoAl}_{2} \mathrm{O}_{4}$ blue pigment. J. Ceram. 2019, 4, 11-16.

5. Lv, H.D.; Bao, J.X.; Qi, S.Y.; Jin, Q.; Guo, W.R. Optical and mechanical properties of purple zirconia ceramics. Asian Ceram. Soc. 2019, 7, 306-311. [CrossRef]

6. Alvarez-Docio, C.M.; Reinosa, J.J.; Campo, A. 2D particles forming a nanostructured shell: A step forward cool NIR reflectivity for $\mathrm{CoAl}_{2} \mathrm{O}_{4}$ pigments. Dye. Pigment. 2017, 137, 1-11. [CrossRef]

7. Zhou, F.F.; Wang, Y.; Cui, Z.Y. Thermal cycling behavior of nanostructured 8YSZ, SZ/8YSZ and 8CSZ/8YSZ thermal barrier coatings fabricated by atmospheric plasma spraying. Ceram. Int. 2017, 43, 4102. [CrossRef]

8. Zhu, R.X.; Liu, Z.G.; Ouyang, J.H. Preparation and characterization of $\operatorname{LnMgAl}_{11} \mathrm{O}_{19}(\mathrm{Ln}=\mathrm{La}, \mathrm{Nd}, \mathrm{Gd})$ ceramic powders. Ceram. Int. 2013, 39, 884. [CrossRef]

9. He, M.T.; Meng, H.M.; Wang, Y.C.; Ren, P.W. Preparation of Magnesium-based Lanthanum Hexaluminate Spraying Powder and Its Heat Treatment Process. Powder Metall. Technol. 2018, 36, 370-376.

10. Jiang, B.; Fang, M.H.; Huang, Z.H. Preparation of Gd3 + doped La1-xMgAl ${ }_{11} \mathrm{O}_{19}(\mathrm{x}=0-1)$ ceramics and its thermal properties. J. Chin. Ceram. Soc. 2010, 3, 1263-1267.

11. Cui, J.J.; Liu, Z.G. Hot corrosion behavior of $\mathrm{LaMgAl}_{11} \mathrm{O}_{19}$ ceramic coated with molten CMAS deposits at temperature of $1250{ }^{\circ} \mathrm{C}$ in air. J. Alloy. Compd. 2016, 685, 316-321. [CrossRef]

12. Melo, D.; Vieira, F.T.G.; Costa, T.C.C.; Soledade, L.E.B.; Paskocimas, C.A.; Melo, D.M.A.; Longod, E.; Marinhoe, E.P.; Souzaa, A.G.; Santos, I.M.G. Lanthanum cobaltite black pigments with perovskite structure. Dye. Pigment. 2013, 98, 459-463. [CrossRef]

13. Li, J.; Medina, E.A.; Stalick, J.K.; Sleight, A.W.; Subramanian, M.A. Colored oxides with hibonite structure: A potential route to non-cobalt blue pigments. Prog. Solid State Chem. 2016, 44, 107-127. [CrossRef]

14. He, L.H.; Wang, H.H.; Mou, B.J. Introduction of several yellow pigments. Ceramics 2013, 5, 46-47.

15. Liu, X.Y.; Lu, F.; Liu, S.F. Sintering and molten salt corrosion behavior of Mg-based lanthanum hexaaluminate ceramics. Chin. Rare Earths 2018, 39, 73-79.

16. Wang, Y.Q.; Yang, W.J.; Ma, J. Ultralow Temperature Synthesis and Properties of Cobalt Blue Materials. J. Ceram. 2019, 4, 497-502.

17. Horlyck, J.; Pokhrel, S.; Lovell, E. Unifying double flame spray pyrolysis with lanthanum doping to restrict cobalt-aluminate formation in $\mathrm{Co} / \mathrm{Al}_{2} \mathrm{O}_{3}$ catalysts for the dry reforming of methane. Catal. Sci. Technol. 2019, 9, 4970-4980. [CrossRef]

18. Li, Y.; Chen, X.L.; Sun, C. Properties of $\operatorname{LnMgAl}_{11} \mathrm{O}_{19}(\mathrm{Ln}=\mathrm{La}, \mathrm{Nd})$ powders with thermal barrier coating ceramic layer material. Chin. J. Mater. Res. 2019, 33, 6.

19. Merino, M.C.G.; Estrella, A.L.; Rodriguez, M.E.; Acuña, L.; Lassa, M.S.; Lascalea, G.E.; Vázquez, P. Combustion syntheses of $\mathrm{CoAl}_{2} \mathrm{O}_{4}$ powders using different fuels. Procedia Mater. Sci. 2015, 8, 519-525. [CrossRef]

20. Ioana, M.; Gabriela, M.; Dana, G. Blue $\mathrm{CoAl}_{2} \mathrm{O}_{4}$ spinel via complexation method. Mater. Chem. Phys. 2010, 122, 491-497.

21. Han, P.W.; Xiao, L.; Wang, Y.L. Cobalt Recovery by the Chlorination-Volatilization Method. Metall. Mater. Trans. B 2019, 50, 1128-1133. [CrossRef]

(C) 2020 by the authors. Licensee MDPI, Basel, Switzerland. This article is an open access article distributed under the terms and conditions of the Creative Commons Attribution (CC BY) license (http://creativecommons.org/licenses/by/4.0/). 